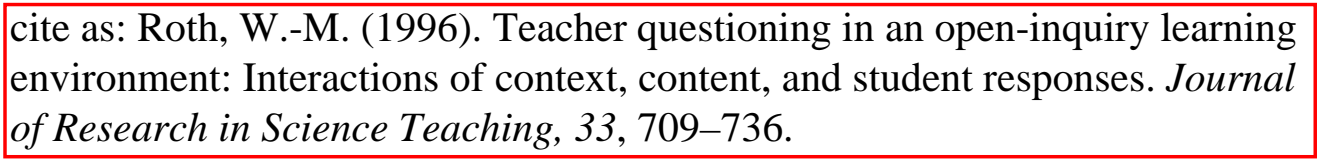

\title{
Teacher Questioning in an Open-Inquiry Learning Environment: Interactions of Context, Content, and Student Responses
}

\author{
Wolff-Michael Roth \\ Simon Fraser University, Burnaby, British Columbia V5A JS6, Canada
}

\begin{abstract}
This article describes a case study of an expert teacher's questioning strategies during an open-inquiry engineering curriculum in a Grade 4/5 classroom. The data sources collected over a 13 -week period included videotaped whole-class and small-group teacher-student interactions, debriefing meetings after each lesson, interviews with observing elementary teachers, and stimulated recall sessions with both teachers present in the class. A holistic, sociolinguistic framework was used to analyze the transcribed videotapes. The analysis provides evidence for the complexity of questioning that is characterized by the interactions of context and content of, and response and reactions to questions. The teacher's competence in questioning was related to her discursive competence in the subject-matter domain; but question content was always mediated by the contingencies of discourse context and response and reaction patterns. The study also provides evidence that questioning is a complex practice which cannot be appropriated easily, a finding which implies a fundamental change in the professional preparation and development of science teachers.
\end{abstract}

When I ask a question, Renata might not choose to go up there and say something. It may have to do with risk, like if the question is really risky and she doesn't know that she is really right.

I want students to feel comfortable ... but may be the boys are more comfortable speaking in front of a group than the girls. I do relate to a little girl, I feel uncomfortable, and I do jump in to help her more probably than I do with a boy.

I tested out a couple of ideas. One is having a small group of all girls together and questioning that group. I find that the girls are more likely to speak up there. (Gitte, reflecting on her questioning technique in a Grade $4 / 5$ class during a civil engineering unit)

These quotations from the reflections of a very competent teacher regarding her practice hint at the complexity of issues to be considered in the study of questioning. Gitte points out that every time she asks a question, the interactions with students are mediated by other aspects of the setting, such as the gender of the student and whether the situation is a small, single-sex group, or a whole-class session. In the course of our daily debriefings, Gitte talked about many other aspects mediating her questioning, such as learning style, student ability, or complexity of content. Thus, to understand teacher questioning it is not simply a matter of measuring and collapsing scores across students, situations, or social and physical settings. Questions are not 
universally good but need to be evaluated in terms of their situational adequacy. The present study shows the complexities of teacher questioning in a student-centered learning environment and underscores the problem of treating every teacher question in the classroom alike by summarizing them indistinguishably into categories, and making claims on the basis of inferential statistics. Process-product research has contributed many findings that helped to understand teacher questioning. One has to think only of the positive effects of longer wait time, higher frequencies of tum taking, or differential use of high-inference questions. However, processproduct research also obscures some important issues. This has led to strong calls for interpretive and sociolinguistic approaches to research into teacher questioning practices (Carlsen, 1991).

Gitte team-taught a unit on civil engineering in a Grade 4/5 classroom. Several elementary teachers of merit who had observed Gitte's teaching rated her questioning practices very highly. The observers explicitly attributed the success of this student-centered unit (as expressed in children's competent tool-related practices and discourse) to Gitte's questioning. The present study was designed to understand these highly rated questioning practices. Social-constructivist, phenomenological, and pragmatic perspectives that view knowing as competent participation in human practices shared within specific communities provided the referents for this study (Berger \& Luckman, 1967; Heidegger, 1977; Lave, 1993; Rorty, 1989). These perspectives are based on an epistemology that recognizes the primacy of human practices-such as teacher questioning, conducting science education research, communicating with others, and so forthto all forms of knowing. 1 will begin by reviewing (a) relevant research on teacher questioning and (b) the role of questions in student-centered, open-inquiry learning environments.

\section{Teacher Questioning}

Teacher questions are frequent, pervasive, and universal phenomena. The frequency of teacher questions is activity dependent, and varies between 30 and 120 questions/hour (Graesser \& Person, 1994). A survey of several studies reveals that in science classrooms, the rate of teacher questions is dependent on activity type and teacher knowledge (Carlsen, 1991). The questioning rate is highest during lectures (82 questions/hour) and lowest during routine seat work (3 questions/hour), and the rate of questioning is negatively correlated with teacher subject-matter knowledge.

Questions have been shown to be an important and integral part of learning, and questions asked by teachers can become indices of quality teaching (Carlsen, 1993; Smith, Blakeslee, \& Anderson, 1993). To bring about conceptual change in science, good teachers use questions to elicit student explanations, elaborations of previous answers and ideas, and predictions that contradict students' intuitive ideas about natural phenomena. Good questions provoke thought, are based in students' experiences, and call for creative thinking (King, 1994). However, most teachers request explicit, factual information; in this context, they appear to be poor role models for good questioning that would provoke learning (Graesser \& Person, 1994).

To organize the topic of teacher questions, Carlsen (1991) proposed a framework composed of three central features: the context of questions, the content of questions, and the responses and reactions to questions. First, the context of questions has two major dimensions: to understand teacher questioning, both the setting as the speaker finds it and the conversational situation actively modified by the speakers need to be considered. From this perspective, understanding a question minimally requires researchers to account for the questioner's (a) constructions of the historical, physical, and social aspects of the setting; and (b) past, pre ent, nonverbal actions (Ochs, 1979). 
Second, few studies have investigated the relationship between questions and content matter. Those process-product studies that focus on the cognitive level of questions are inconclusive, and reviews and meta-analyses of the same research literature do not agree whether there is a general trend in the knowledge claims of these studies (Redfield \& Rousseau, 1981; Samson, Strykowski, Weinstein, \& Walberg, 1987; Winne, 1979). Sociolinguistically-oriented studies, although providing a way of describing the contextualization of subject-matter topic, require enormous investments in time, considerable subject-matter knowledge, and complex analyses; consequently, they are rare in science education (e.g., Carlsen, 1988; Lemke, 1990). Nevertheless, these existing studies show that teachers maintain tight control of classroom discourse in terms of framing, sequencing, and validating standards of subject matter. Tum taking and topical development and change-inseparable features of discourse for sociolinguists-are frequently patterned according to the IRE sequence: The teacher initiates (I) an interaction with a question, a student responds (R), and the teacher evaluates the response (E).

Third, while process-product research focused primarily on wait time as the major dimension of students' responses and reactions to questions, sociolinguists are more concerned with social status, patterns of participation, and quality of responses (Carlsen, 1991). Here, studies show that teacher questions typically produce terse and factual statements on the students' part. To discourage students from questioning, teachers employ a variety of strategies: domination of the speaking floor, frequent requests for low-level factual information, and a disregard for student bids to change the current topic (Carlsen, 1988). On the other hand, student participation increases in lessons in which teachers do not evaluate student responses, when teachers relinquish control, and when teachers ask personal questions and show genuine interest.

\section{Teacher Questioning and Open-Inquiry Learning Environments}

In everyday life outside of schools, most questions are of a genuine information-seeking type designed to elicit missing information. Several assumptions need to be fulfilled before a question can be categorized as genuinely information seeking. Among these are: the person asking the question (a) does not know the requested information, (b) believes that his or her counterpart can provide the information, (c) is genuinely interested in the requested information, and (d) believes the answerer will provide the answer (Morrison, 1981; van der Meij, 1987). Traditional teacher and textbook questions usually violate all of these assumptions. The questions students are asked have the interesting property that the correctness of the response is prefigured in advance: these questions do not seek information but rather answers to be assessed in terms of what the questioner already knows. This evaluative part of teachers' questions gives them control of the learning situation; teachers become the gatekeepers for the system (Lemke, 1990; Lynch, Livingston, \& Garfinkel, 1983; Poole, 1994a, 1994b). In a student-centered classroom, however, this closed form of questioning concerned primarily with control should no longer have a place. Harlen (1985) developed a type of question he called "productive," in which students are required actively to engage with the materials at hand rather than answering the kind of formatted questions described by Lynch et al. That is, Harlen recommended against the use of questions that ask for single answers, but encouraged questions that call for reflection and analysis that promote a view of science as a dynamic search for answers (e.g., "Can you find a way . . . ?").

In recent years there has been an increasing interest in student-centered, open-ended learning environments in which students individually or in small groups determine the foci of their science-related inquiries or design of artifacts (Hare!, 1991; Kafai, 1994; Roseberry, Warren, \& Conant, 1992; Roth, 1994, 1996b; Roth \& Bowen, 1995; Scardamalia \& Bereiter, 1992). These 
studies focus by and large on student cognition and provide only scant conceptualization of the role and function of teachers in these learning environments. While the notion of apprenticeship and its correlate teaching techniques of modeling and scaffolding are sometimes used to describe student-teacher relationships, it is not quite clear what the role of teacher questions should be in student-centered learning environments. In many classrooms, teachers' questions have the purpose of controlling the social situation given by the entire class and of differentiating students (Lemke, 1990; Poole, 1994b), outlining and perpetuating an epistemology built on the absolute and normative character of facts (Poole, 1994a), or controlling student activity in tutoring situations (Graesser \& Person, 1994). However, in a student-centered activity where students pursue different projects in small groups, the role of teachers' questions is different (Harlen, 1985). Concerns for controlling the entire social situation would constitute a contradiction in terms. What then is the function of teacher questioning in a decentralized classroom? What is the role of teacher questioning in a setting where the construction of new knowledge originates with children's experience and prior knowledge? What is the role of questioning if canonical knowledge is relevant but peripheral to the construction of a classroom discourse on engineering? Finally, what is the role of questioning if canonical knowledge is not used as a standard against which students' discourse contributions are evaluated? The present study was designed to answer these and related questions.

\section{Design}

The present study was framed by an epistemology of social practice (Bourdieu, 1990; Lave, 1993; Rorty, 1989). I began the analyses with the assumption that reasoning is observable in the form of socially structured and embodied activity (Garfinkel, 1991; Heidegger, 1977; Suchman \& Trigg, 1991), and considered the videotapes and transcripts to be natural protocols of teachers' and students' efforts in making sense of events; structuring their physical and social environment, or communicating with each other. These protocols provided me with opportunities for construing the conversational and cognitive work done in the context of teacher questioning.

This investigation was part of a larger study of a 3-year, schoolwide and teacher-initiated effort to improve science teaching. As part of the overall effort, and in exchange for participating in our investigations of student and teacher cognition, my research team participated in the teacher development. When requested, we facilitated teacher-organized professional development days, assisted teachers in planning their science curriculum, and collaborated in teaching entire science units. In one of these collaborative arrangements,' Gitte, a curriculum developer and part-time graduate student, team-taught with Tammy a unit on civil engineering to a split Grade 4/5 class. Gitte had 4 years of classroom experience in elementary schools (at the same grade level) during which she had conceived and pilot tested the unit on civil engineering. For the 3 years prior to the study, she had fully developed the curriculum and presented it in about 40 teacher workshops. Tammy had 12 years of experience teaching at the elementary level, 6 of which were part-time and in the same setting. Tammy had taught part of the unit once before and had attended two relevant 3-hour workshops.

The issue of questioning arose in the course of the study. Repeatedly, knowledgeable teachers-science representatives or coordinators at their school-who observed the engineering lessons focused on Gitte's questioning technique as the outstanding feature. It is consistent within the social-practice perspective of this study that the assessments of other competent members in the (teaching) practice would be taken at face value regarding the Gitte's competen- 
cies (Roth, 1995). Tammy's assessment was particularly important: she was recognized by her peers as a leader in science teaching, was responsible for the science curricular materials, and functioned as the liaison with the university team. Her prior experience of teaching an engineering unit allowed her to compare the development of children's discourse and tool-related practices. Tammy credited Gitte's questioning techniques for the success of the unit ("I told you that many times, how Gitte extends the ideas. I mean that thing, the good questions that Gitte thinks about and asks, it is phenomenal, it blew me right at the head"). Because of its importance during the professional conversations, the research team chose teacher questioning techniques as one of its research foci.

\section{Classroom Setting}

The site for this investigation was a mixed-grade French immersion classroom with 23 Grade 4 ( 10 boys and 13 girls) and 5 Grade 5 students ( 3 boys and 2 girls). The students usually spoke French during the school day, but science was taught in English to accommodate Gitte in the class.

The curriculum "Engineering for Children: Structures" (EfCS) was developed so that elementary school children could find out about and have positive first experiences with engineering. (This unit was developed by the Association for the Promotion and Advancement of Science [APASE], a nonprofit organization whose principal mission is to bring an expanded vision of science and technology education to elementary schools.) As a practical application of science, EfCS is a vehicle for introducing science concepts, providing ill-defined problemsolving contexts, and fostering positive attitudes toward science and technology. Each activity in the program is designed as an open-ended engineering problem and as a context for learning to work and solve problems in a collaborative manner.

The EfCS unit was taught twice per week, normally for 90 minutes, for a 13 -week period. In some instances, however, the students spent all morning (3 hours) on their engineering projects. Two female engineers with geotechnical and biomedical orientations visited the class on separate occasions to talk about their own work (about 30 minutes), and interacted with the students about engineering issues related to the children's projects. Gitte had specifically invited these two women to promote a positive image of women in engineering. Both teachers felt this to be an important instructional move because although there were no gender-related achievement differences (Roth, 1996a), there were gender-related differences in the level of engagement in classroom discourse. The EfCS unit also included a field trip to the local science museum where an exhibition on bridges featured the children's own bridge projects completed during the unit; in addition, several films on bridge building were available for viewing during lunch periods.

The children spent most of their time on practical work with a partner of their own choice. Both teachers went from group to group to talk with the students at length about engineering issues, technical problems arising from the children's work, how to work in groups, and how to deal with frustrations. In each lesson, time was set aside for whole-class conversations about children's work. During this time, one of the teachers pointed out features in children's techniques to join or strengthen materials, the same techniques that are also used by professional engineers; students also presented what they had done up to this point, the problems they had encountered, and how they had solved them. These whole-class sessions were also occasions for children to compliment their peers, ask questions, or provide suggestions for improvement of their peers' structures. 


\section{Data Sources, Construction, and Interpretation}

I began to participate regularly (one or two afternoons per week) in the classroom activities 4 months prior to the EfCS unit to become enculturated to the school and, more specifically, to Tammy's classroom. Consistently with this study's undergirding epistemology of social practices, I wanted to find out about the teaching and learning practices in this school, and particularly in Tammy's classroom. Therefore, ethnographic field notes were the choice data source for this period.

During the EfCS unit that lasted for 3 months, two cameras were used continuously to videotape whole-class and small-group teacher-student and student-student interactions. In the entire corpus, 11.5 hours featured whole-class interactions and nearly 5 hours of interactions between Gitte and individual small groups. In addition, observational information provided by 2 to 4 observers became part of the data base in the form of written field notes. After each lesson, I debriefed Gitte. Her personal notes, my field notes, and the transcripts of the videotaped meetings also entered the data base. Additional debriefing sessions with Gitte, Tammy, and visiting teachers-during which we used videotaped classroom events to stimulate recall and discussion-were also videotaped and transcribed. Finally, our video-based records included conversations between the two teachers that had arisen spontaneously at the end of lessons, but still in the classroom where the topics of conversation (student-produced artifacts or students themselves) were still present and thus indexically available to their discourse. Here, Gitte and Tammy often talked about how a particular questioning sequence has helped children in conceptualizing a problem or finding a solution for it, or both; these conversations provided us with much information relevant to the present study. All videotapes were transcribed as soon as possible after they were recorded. To ascertain that the transcriptions were accurate, they were checked by at least one other member of the research team. In the case of alternate hearings, differences were resolved in collaborative sessions. The remaining uncertain or indecipherable utterances were indicated as such in the transcripts.

The large body of detailed and accurate transcriptions provided a sufficient basis to develop and use descriptive coding schemes for the type of utterances and knowledge domains. The codes, which are shorthand notations for particular descriptions-e.g., $\mathrm{R}_{2}$ (elab) =request for elaboration no. 2 , or "content of knowledge is related to science and engineering theory"-are developed for interpretive research in the usual way. Tentative descriptions and corresponding codes are developed and subsequently tested in the body of existing data. They are then refined through an iterative process until a useful and comprehensive scheme has emerged that covers the entire data base.

The epistemology according to which meaning arises out of systems of social practices is commensurate with an interpretive research methodology. In interpretive research, the concept of internal validity that guides researchers in a quantitative paradigm is replaced by that of credibility (Guba \& Lincoln, 1989). It substitutes the isomorphism between constructed realities of the participants and the reconstructions attributed to them for the equivalent isomorphism between objective reality and findings in traditional research. Social scientists recognize a number of techniques that allow researchers to establish the credibility of their knowledge claims. Among these techniques are prolonged engagement, persistent observation, peer debriefing, progressive subjectivity, and member checks (Guba \& Lincoln, 1989). Prolonged engagement (7 months), persistent observation, and debriefing (after each lesson) are implicit in design of the study and are evidenced in my earlier account of the data sources and their origin. Through our collaborative work in daily debriefings and interpretation of the data sources, Gitte and I ascertained our mutual positions and constructions. That is, by engaging each other in 
conversations about teaching practices, we developed shared understandings consistent with the social practice perspective of knowing in this study. These constructions were tested in the body of the data sources, by directing the data collection efforts during the next field day, and by discussing them with Gitte. On the basis of this new information, I discarded, modified, or retained working hypotheses. As a result, the constructions presented here arose from the progressive subjectivity in our interactions. Gitte and Tammy's involvement in the research project allowed me to conduct member checks in an ongoing manner. Because I did not conceal information and hypotheses, there were also situations in which both teachers used this information to change the setting. For example, based on the analysis of an early videotape which had shown Gitte selecting boys to respond about four times more often than girls, she tried to change this pattern in subsequent lessons by monitoring her teaching through the review of videotapes.

\section{Research Constructions}

Questioning is an important aspect of teachers' daily practices. However, despite their prevalence and importance, fine-grained analyses uncovering the details of these practices are rare, and many open questions remain. The present study was conducted to understand teacher questioning in the context of an innovative child-centered engineering curriculum. I engaged in this study because: (a) the analysis of data sources had indicated significant changes in the children's tool-related and discursive practices (Roth, 1996a, 1996b) and (b) there was reason to believe that the gains were in part precipitated by the expert teacher's (Gitte) skillful questioning. To understand Gitte's questioning, I constructed and analyzed data according to Carlsen's (1991) three dimensions: context of questions, content of questions, and responses and reactions to questions. These dimensions and their interactions are the topic of the following three sections. The decision to present the results in these three sections bearing the names of Carlsen's dimensions was largely driven by concerns for readability; they do not reflect the observations in interactions as the rule rather than the exception. The extent to which the dimensions and their interactions are discussed here reflects the salience these had in our conversations and the subsequent analysis of the entire data base.

\section{Context of Questions}

There are two issues of context of questions relevant to the present study. First, Gitte had specific instructional intents for asking questions: they permitted her to draw students' attention to important engineering practices. Furthermore, there were mediating influences which hindered her to ask all students the same questions with the same frequency; that is, there were interactions between context and content of questions. While it is almost a truism that good teachers adapt their interactions with students, and, in the present context, their questioning to the specific circumstances of each encounter, research on questioning from paradigms other than sociolinguistics is generally insensitive to these issues. Second, context also pertains to the situational contingencies of each conversation, its topical development, and the local management of tum taking. This section will focus on the static aspects of context, Gitte's motivations for questioning, and mediating considerations.

Gitte felt compelled to follow what she perceived as a trend in recent literature and government documents on teaching science: to provide a student-centered setting and activity orientation. In her experience, however, letting children engage freely in hands-on activities does not lead to canonical knowledge, which she believes exists and is authoritative. Like so many other teachers, Gitte had interpreted constructivism to mean anything goes. Questioning 
children in the context of their own inquiries helped her to resolve a conflict: When childcentered inquiry is combined with appropriate questioning techniques, canonical science and engineering content knowledge do not have to be compromised.

Gitte believed that children spontaneously invent many discursive and tool-related practices which are similar, or can easily be related, to their canonical counterparts. However, children will not make these connections on their own, or value their inventions as important aspects of adult activity. Good questions allowed Gitte to combine open inquiry and the learning of important engineering aspects:

[The EfCS unit] is fun; the kids love building. But I think if we just leave them at building that thing, and we don't go in there and talk about the cantilever or the triangle as a practice of reinforcing or the pin joint as a moveable joint, or the reinforced concrete that Sandy did, they don't necessarily go away with anything they don't already know. And they also don't make the connection with what the building has got to do with a profession, engineering or science.... [For example, ] if I saw a kid that is trying to make something straight, I might be able to ask questions that would lead that child to thinking about using a string, just by the words that I used.

In Gitte's view, questions have at least 6 functions: (a) to focus children's attention on a canonical concept by "drawing/pulling it out from their experience" ("You know what a plumb line is? Wouldn't it be neat if we saw a kid developing such a technique. It's likely to happen, because I made that connection. If I saw a kid that is trying to make something straight, I might be able to ask questions that would lead that child to thinking about using a string, just by the words that I used."); (b) to help children develop a language for talking about their engineering artifact ("those words like reinforce, brace, bundling, those ideas came from the kids, through questioning"); (c) to "stretch them to improve" their artifacts; (d) to make sense of their experience and learning ("questioning helped that conceptual breakthrough to happen"); (e) to succeed ("I asked a lot of questions that helped them to succeed"); and (f) to cope with temporary failure ("[questions make sure that the] failure that happens is not that frustrating").

Gitte believed that distributed knowledge would be integrated by children when they get to share their experiences in whole-class sessions. Thus, she specifically planned show-and-tell ${ }^{l}$ sessions so that discursive and tool-related practices of individual students could be appropriated by others. She planned these sessions in such a way that by calling on specific students, the presentation and surrounding discussion focused on those specific engineering techniques that she had previously identified. Her questions in whole-class sessions served to pull out significant experiences and point to similarities in experiences across groups ("I have, at the end of these activities, drawn out those techniques over and over again").

Gitte believed that her questioning in small groups and whole-class situations served as a model for children to develop questioning strategies ("Kids will model your questions"). Once children appropriated her questions or pattern of questions, a class became more independent in its activities, because children provided each other with the scaffolding support that leads to new and better solutions, awareness of knowing and learning, and appropriation of discursive and tool-related practices ("The kids ask each other questions, they compliment each other, they talk

I Throughout the manuscript, concepts such as showand-tell or drawing out used by the participants themselves to order their world are italicized to distinguish them from my own language to understand their world. According to Geertz (1975), the informants use inside or emic terms. Terms developed by the analyst to order the participants world from his perspective, such as my "nested and contingent queries," are outside or etic concepts. I continue to use quotation marks to enclose direct quotes from the data sources. 
about [engineering] techniques .... I I have often played the role of being the one to pull that out, but they can do that for each other"). Although Gitte and her partner Tammy did not specifically encourage children to scaffold each other's activities through questioning, they repeatedly and publicly tagged some questions as good questions. There is ample evidence in my data base that a culture of questioning developed. More and more children asked questions which had been modeled by Gitte; in a similar way, Tammy appropriated many of Gitte's questions ("What was the biggest problem you had so far?" [Gitte]; "What difficulties did you have, and how did you solve them?" [Sandy]; "What was your biggest problem? [Maggy]"; "Can you tell us, what was kind of a big problem for you?" [Tammy]).

Gitte isolated a number of mitigating influences on her questioning: these led to questioning patterns at the whole-class level that differed from the small-group situation. One important mitigating factor was gender. Our observations had shown that in whole-class interactions, Gitte called on girls much less frequently than on boys. Despite her declarations to change this pattern, Gitte nominated significantly more boys than girls as respondents. In 12 probes over a 50 -day period, the ratio of girls to boys was at best $50 \%$, and in several cases she nominated more like I girl for every 18 nominations of boys (Figure 1).

Although she had some rules of thumb to manage her questioning techniques ("Never ask the person to put the hands up first"; "I consciously count to 5"), Gitte felt uncomfortable asking a girl to respond when there were many boys who volunteered. Having been a quiet girl herself, she did not want to put girls on the spot; she wanted them to feel comfortable and learn in their own "learning styles." She wanted girls to feel safe when they responded. When she called on a girl and "saw her uncomfortableness, sort of squirming," Gitte was uncomfortable herself and let the girl "off the hook, real fast." To address girls' learning styles and make questions Jess risky, she asked them more close-ended questions ("because they are not as comfortable with open-endedness"). Because of her conflicts, Gitte began to work with small groups of girls. She found that "the girls were more likely to speak up there ... you couldn't shut them up." Gitte thought that she provided girls with ample opportunities to construct their stories during smallgroup sessions, so that the low frequency of designating girls as respondents during whole-class

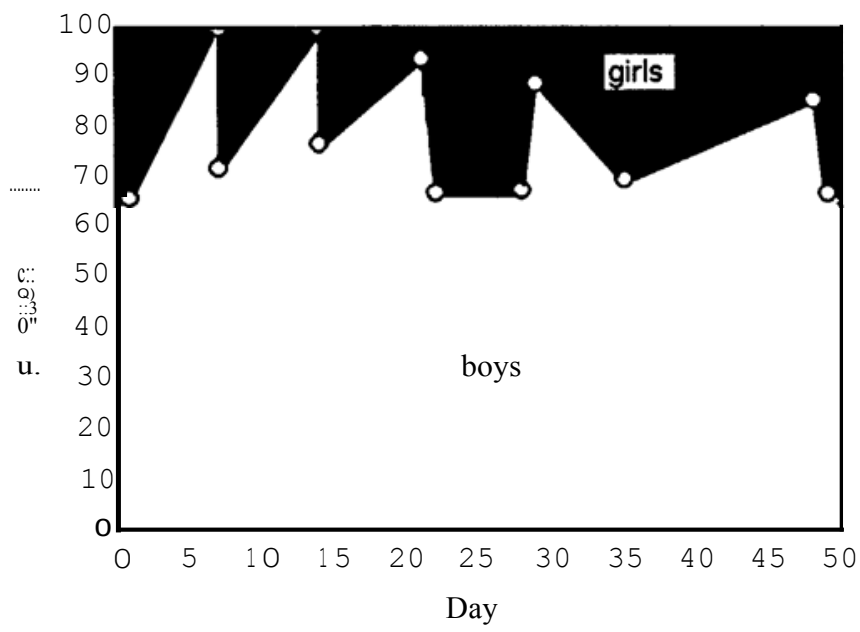

Figure 1. Frequency with which Gitte called on boys (white) versus girls (black) over a 50-day period on 12 sampling occasions. 
interactions was not a serious problem. In any case, Gitte felt that she would do greater damage if she made the learning environment unsafe for girls by putting them on the spot.

Children's abilities and interests constituted another important mitigating aspect of Gitte's questioning. In the beginning of each interaction, she had to "feel out" the children. This allowed her to "find the fine line between extending their thinking and putting them down" and "find out whether they are interested in [doing more], because sometimes they are interested and just not sure." She considered stopping questioning a group because "they were getting a bit giddy." Gitte also changed the content of her questioning when she felt that students were frustrated or no longer attentive. For example, in one of her interactions with Andy, Simon, and Tim, Gitte unexpectedly asked them about the "leaning effect" of their tower and followed up with, "So, you are trying to tell me that your tower is unique and actually want to buy it because it's different than boring old straight ones." Later, during a stimulated recall session using the videotape of the interaction, she justified the questioning sequence: "I saw that they were getting a bit giddy . . . . I got into the leaning a bit, there; I have seen a lot of towers lean; it is easier to do that, and a lot of times people are really down on themselves."

In summary, Gitte believed that questioning allowed her to teach in a child-centered manner without compromising content knowledge. Whole-class sharing sessions and the belief that students appropriate her questioning technique were integral parts of her teaching. Several mitigating factors, such as students' gender, abilities, and interests influenced her situated decisions about questioning strategies.

\section{Content of Questions}

This section on the content of questions is divided into two parts. In the first part, I present a typology of the question content asked by Gitte. This typology and its great similarity with a typology of knowledge that is important to innovative engineering design (Faulkner, 1994) underscores the significance of teachers' competence in the discursive practices of the field they teach and the questions they ask. In the second part of this section, I will illustrate and discuss the interactions between question sequences and content. Here, the considerable difference between Gitte's questioning in open-inquiry and traditional IRE sequences (Lemke, 1990) and devised format questions (Morrison, 1981) stand out.

\section{Typology of Question Content}

For deep learning (such as conceptual change) to occur, teachers need to elicit student explanations, elaborations of previous answers and ideas, and predictions (Smith et al., 1993). However, teacher questions most commonly focus on recall of factual information in the devised question format (Morrison, 1981). Here, the requested answers are to be assessed in terms of what the teacher already knows, leading to a common pattern of classroom discourse modeled by the IRE sequence. The analysis of the data sources in this study documented a virtual absence of instances in which Gitte evaluated students' answers in terms of prefigured standards; there were only isolated instances of teacher utterances designed to manage conversations ("Can we have one at a time?"); there were a few isolated comments ("Engineers call this a raft foundation"); and there was about one question for each interaction with a group that addressed emotional issues ("Are you proud of yourself?"; "What was the most frustrating part of this whole exercise?"). All other questions related to various aspects of artifact design in a civil engineering context. To better understand what subject matter was addressed by Gitte's question, I established a typology of question content relating to engineering matters (Table 1). 
This typology is evidence of the high-level content of Gitte's questioning that was more concerned with engineering practices than with engineering facts.

This typology was established by bringing together two existing typologies on innovation in engineering and architectural design (Faulkner, 1994; Schon, 1987) and the present data. This typology does not consist of orthogonal, but rather-as the two existing typologies of adult engineering and architecture-overlapping categories. There are many indications that such polythetic classification schemes (which allow an observation to be assigned to multiple categories) are far more appropriate in handling the complexity of human discourse than monothetic classification schemes (which allow an observation to be assigned to one, and only one category) (Faulkner, 1994; Graesser \& Person, 1994). Table 1 includes category titles, brief descriptions, sample questions, and specific concepts from the discourse domain. Following Faulkner (1994), there are five major types of knowledge in engineering design innovation: knowledge relating to the natural world, design practice, development and testing of the design, final product, and knowledge itself. (The following titles and terms are category items that appear in Table 1.)

Knowledge Related to the Natural World. This category includes theories from the domains of science and engineering and the properties of natural and man-made materials used in engineering design. While Gitte raised few questions of theoretical nature, questions leading to conversations about the forces (tension, compression, and gravity) acting on the structures became regular features in this class. Properties of the materials constituted a central theme, and Gitte had designed several lessons in which the children experimented with their materials.

Knowledge Related to Design Practice. Design-related knowledge is a central and vital aspect of innovation in engineering design. In the present setting, children began to design without formal knowledge in the domain. Their efforts thus have to be understood from a perspective of innovation. Gitte frequently asked students for the purpose of their designs ("I was playing the 'reality bit"), often implying specific needs and design criteria and specifications that potential users of full-scale artifacts might have. Design concepts such as fundamental operating princiPles-and normal configurations of materials to guarantee stability and strength of the artifacts were, besides the material properties, a second central theme of the lessons. Questions concerning design instrumentalities encompassed requests to elucidate the procedures and alternatives considered by the children during the process of designing. Finally, design precedence categorizes those questions that were related to knowledge of existing structures in the community or known to the children by other means. Local, national, and international landmarks were frequent features of the classroom discourse.

Knowledge Related to the Development and Testing of Design. In this category, I counted questions which related to the technical aspects of developing the artifacts largely falling into the domain of tool- and material-related practices. Development and test procedures are methods of testing and accepted ways of developing an artifact including, for example, the use of cofferdams for underwater construction or the use of shaker tables (children's term for modeling earthquakes by shaking tables) to test whether structures are earthquake-proof. Development and testing instrumentalities include knowledge of alternate practices to deal with contingent problems in the development process. Gitte frequently asked questions which asked students to interpret test data, predict the outcome of tests, or predict the performance of their artifacts in more general terms. 
Table 1

Typology of Question Content

Content of question is related to knowledge of

Description

Sample question(s)

Specific concepts from the

discourse domain

I. Natural world

I. I. Science and engineering theory

1.2. Properties of natural and artificial materials

2. Design practice

2. I. Design criteria and specifications

2.2. Design concepts

2.3. Design instrumentalities and general design competence

2.4. Design precedence
Laws of nature (forces), theoretical tools (distribution of forces through structures)

Strength of building materials and strength, bonding ability, and stability of connecting materials

Use(r) requirements, specification of design components, "reality bit"

Fundamental operating principles, normal configurations

Structured procedures such as decomposing problem, ways .of doing things, ability to judge between competing demands

Prior experience with design artifact in the classroom, or design of real-world structures
So it brings the weight down on the ends and it's easier for a force to go across [the beams]

What is it about the glue that is really good? Are you happy with the materials?

Is this a bridge for cars or people? Do you think you will put any railings on it?

How do you think about these little feet?

We're gonna bring a big triangle up in the middle

Are you going to use anything different to do with the side stabilizers? Can you make this larger? What is your plan?

[Is your design] like the West Coast Energy one? Do you know, right now there are 12 proposals for a new Lions Gate Bridge?
Forces, compression, tension, gravity

Glue, Scotch tape, masking tape, pin joints; straws, newspaper rolls, skewers, string, toothpicks

Cars, people, river, earthquakeproof, wind, bridge, railing, elevator, gondola

Triangle, (cross) brace, doubling, layering, bundling, stay, cantilever, deadman,

foundation, pier, bridge deck, floating pier, pillar, dome, base, suspension, anchor, stability, X-shape, column

All of I. I, 1.2, 2.1, 2.2

Buildings: Empire State, Eiffel Tower, West Coast Energy, $\mathrm{CN}$ Tower, various sports arenas (Superdome, Skydome, BC Place)

Bridges: Lion's Gate, Second Narrows, Tacoma Narrows, Lynn Valley, Capilano 
3. Development and testing of design

3.1. Development and test procedures

Methods of testing, ways of developing the design artifact

3.2. Development and testing instrumentalities

3.3. Test data

4. Finalproduct

4. I. New ideas

4.2. Operating performance

4.3 Production competence

\section{Knowledge}

5.1. Sources of knowledge

5.2. Discourse
Techniques and artifacts used in $\mathrm{R} \& \mathrm{D}$ of design

Predicting test outcomes

Entire design, techniques and artifacts to produce it

Knowledge obtained through testing, user experience

Pilot production, scale-up

Location of knowledge, availability of tools and materials, sources of help

Canonical engineering concepts

\section{Students' own descriptors}

Learning from successful resolution of problems; source and process of ideas.
How are you going to test if your tower is earthquakeproof? How did you solve this [design problem]?

What did you do when it collapsed?

What would happen if you put weight there? Which part would go first if you were testing it?

Why should I be interested in [your bridge]? What is the selling feature here? Is there anything else you should tell me about this bridge?

What else did you add to make it stand up a little more?

Did you have any problems when you made the larger windmill?

Did you use any of the techniques from the techniques board?

Do you know what [catastrophic failure] means? What did [the engineer] call that?

Do you have a name for this technique of making?

How did you come up with the idea of the death park?
Testing: Earthquake-proof, shaker table, forces, weakness, stability, catastrophic failure

Techniques: Layering, bundling, doubling, embedding, reinforcing, overlapping, strengthening, cofferdam

Collapse, weakness, stability, strength

New, interesting, selling feature

Stability, strength, weakness

In-class: techniques board, peers, visiting engineers

Out-of-class: Well-known local and global bridges and buildings, (see 2.4.)

Teachers and engineers: Brace, cantilever, deck, cofferdam, raft foundation, etc.

Students: Triangle, layering, platform, X-shape, stay, bundling, etc.

Idea, problem 
Questions Related to the Final Product. While Faulkner's (1994) typology focused on final, full-scale production of technological artifacts, my typology uses final product as the end stage of children's design artifacts that are considered models. Gitte frequently encouraged students to talk about relevant design features by asking them about the new ideas represented in the artifact. These ideas could be about the artifact as a whole or individual materials or techniques relevant to its construction. Operating performance pertains to content knowledge obtained through the testing of the final artifact; in general, these questions also asked students to account for the degree to which an artifact met the original design specifications. A few production competence questions related to the pilot production and scale-up of artifacts constructed by the children (such as Tom's windmill or Chris and Arlene's gondola, which existed as pilot projects).

Knowledge of Knowledge. Gitte also asked questions about knowledge itself. These questions pertained to the source of knowledge, the knowledge of meanings and names of specific discourse items (originating from canonical discourse domains or from students' familiar language), or accounts of difficulties and problems students faced during the process of designing constructing their artifacts (learning process).

\section{Interactions of Question Sequence and Content}

My main claim in this part of the article can be framed in these terms: Gitte's questioning was designed to scaffold students' discursive activity to lead to independent accounts and student-centered discussions. I will illustrate the progression from interactions characterized by frequent teacher questions to student-centered discussions by drawing on three episodes. These episodes respectively feature: (a) a small-group teacher-student interaction in which students' accounts of their work and project are heavily scaffolded by sequences of contingent and nested teacher queries, (b) a small-group teacher-student interaction that shows increased independence of students' accounts, and (c) a sustained student-centered discussion surrounding the presentation of a student-produced artifact. I will show in a fourth episode that there was an awkwardness in the few situations when Gitte attempted to elicit specific content knowledge, which she referred to as "drawing knowledge out." (The transcription conventions and codes and typology of utterances used with the episodes can be found in Appendices A and B, respectively.)

Contingent and Nested Queries. The analysis of Gitte's questioning reveals an interaction of questioning sequence and content. Many questions were nested such that Gitte asked a question related to the knowledge about the final product, but implicitly encouraged students to talk about other aspects of the artifact such as the materials, engineering techniques, or issues related to the development and testing of the artifact. For example, Gitte asked about performance, but wanted students to think about design concepts ("What happens if you have an earthquake?" or "Have you taken into account the idea that there might be an earthquake?"). This question about performance embedded another one about design concepts, driven by Gitte's concern about whether the students included configurations that will stabilize the structure. Thus, the question implicitly asked for design principles, although it was couched within a context pertaining to more global issues of design. In a similar way, Gitte used a consumerproducer relationship to couch questions, to fish for knowledge related to any topic including new ideas. "Why should I be interested in buying your structure?" or "What is the selling feature 
here?" embedded more specific questions related to operating performance and, ultimately, design practice and properties of material. This is illustrated in Episode I, a very typical example of Gitte's questioning. Her first question initiated the conversation and requested information about important features of the design as they were identified by the children. As such, Gitte could not know in advance what the answer would be. Rather, she used the students' first responses as a platform for further inquiry. Here, Sylvia focused on the strength of her bridge as an outstanding feature. Gitte followed up by requesting an elaboration of the first answer (line 1.3), because neither Sylvia nor Brigitta appeared to be inclined to add more information on their own. This question, although about stability (an item relating to operating performance, typology item TI-4.2), implicitly encouraged students to frame their answers in terms of knowledge relating to the properties of materials (TI-1.2) or design concepts (TI-2.2), or both. In response, Brigitta mentioned the tape and pointed to the braces as those features in her artifact which provided strength (line I.4). Consistent with her interest in developing children's discursive practices, Gitte asked the two girls to name the item which they had made available in the discourse only in an indexical manner (line 1.5). As with the initial request, Gitte could not know the answers to her questions, but appeared genuinely interested in finding out. The codes used in the typology of utterances make this nested nature apparent: $R_{1}$ [init] $R_{2}$ [elab: $A_{11} R_{3}$ [elab: $A_{2}$.d. Here, $R_{1}$ initiated the sequence, and $R_{2}$ and $R_{3}$ constituted queries contingent on the previous answers $\mathrm{A} 1.1$ and $\mathrm{A}_{2.1}$, respectively.

When the students had exhausted their topics of interest, Gitte began to point out specific features and relate her requests to them (much in the line of her intent to have children learn about specific engineering techniques). The requests then took the following form: "I like the lightning rod on the top. What is its purpose?" [TI-2.1]; "Your tower has a leaning effect. What is the purpose of that?" 1Tl-2.1]; or "The angle is a bit steep. Do you think your cars will have problems on this slope?" [TI-4.2(2.1)] At other times, she directly addressed the feature of interest: "How do you think about these little feet (that stabilized the bridge)?" [T1-2.2]; and "I am interested to know why you put these (braces) going that way like that instead of just this?"

Episode I

\begin{tabular}{lcc}
\hline Utterance & $\begin{array}{c}\text { Type of utterance } \\
\text { (Appendix A) }\end{array}$ & $\begin{array}{c}\text { Knowledge domain } \\
\text { (Table I) }\end{array}$
\end{tabular}

I. Gitte: I am interested in the following engineering $\quad R_{1}$ [init) questions: I'm interested in purchasing your bridge. But in order to do that, I need to know what is interesting about your bridge that you did? What is the selling feature here? Why should $\mathbf{I}$ be interested at all?

2. Sylvia: Because it is strong, because it is quite $\quad \mathrm{A}_{1.1}$ strong. It looks like it is not strong, but it is really strong.

3. Gitte: And how is it strong? What makes it strong? $\mathrm{R}_{2}$ [elab: A .]

4. Brigetta: We, we used tape under here and these here $=(($ points to braces $))$

$\mathrm{A}_{2.1}$

5. Gitte: $=\mathrm{OK}$, the tape, and what did you call these here ((points to braces))?
4.1 (new product ideas, outstanding features)

4.2 (operating performance)

$4.2(1.2,2.2)$ (operating performance, but suggesting

I.2 (property of tape), 2.2 (design concepts)

$\mathrm{R}_{3}$ [elab: $\mathrm{A}_{2 .} \mathrm{J} \quad 5.2$ (name of technique) 
[TI-2.2]. In this way, Gitte made sure that in their accounts the children covered a wide range of topics from the typology of content.

From Nested and Contingent Queries to Independent Accounts. Over time, the students began to elaborate their answers without Gitte's requests for elaborations and justifications. An occasional indication that she was still following and interested in the children's account sufficed to maintain the construction of an artifact's (hi)story (One can consider the children's talk to be stories about or histories of the artifacts they produced). The lengthening of these accounts without further requests is illustrated in the transcript of Episode II. The interaction commenced with a general question about problems (line II.1). Here again, the initiating query had a genuine character: Gitte did not know on which course of action the two girls had settled. Before her next initiating query (line 11.22), Gitte asked two contingent queries; the second was a reiteration of the first (lines 11.4 and 11.6). Gitte's other contributions can be read as continuers (Erickson, 1982). With these continuers, Gitte relinquished her questioning and invited students to continue their accounts (lines 11.3,11.11, 11.17, and 11.19), and confirmed her understanding (lines 11.3 and I1.11) or that she still followed their account (lines 11.17 and 11.19). In the process of this interaction, and facilitated by Gitte's contingent queries and continuers, Shelly and Clare's account covered 4 of the 5 domains in the typology (see third column in Episode II): They talked about the techniques and artifacts used (TI-3.2, lines I1.12, 11.13, 11.I8, and 11.20), the properties of materials (T1-1.2, lines 11.9, Il.1O, I1.12, and 11.15), performance of the final product or parts of it (T1-4.2, lines 11.4 and 11.1O), and the location of specific information or tools necessary for their project (T1-5.1, lines 11.2, II.4, and Il.16). It is important to note that none of Gitte's discourse contributions had an evaluative function.

Sustained Student-Centered Discussion. Students' contributions to conversations became increasingly independent of teacher scaffolding, an observation which was especially apparent in whole-class discussions. Here, an additional element was introduced to the conversations: student questions. These lengthened the exchanges which were not simply responses to teacher questions, but self-sustaining conversations to which Gitte also contributed on an equal footing with students. That is, student responses interacted with the context such that self-sustaining conversations evolved in which students asked each other questions. (Gitte's interactions with students cannot be studied independently because of Tammy's presence. However, Tammy had shifted to similar patterns of interactions as a result of their collaborative effort to improve questioning.) An example of sustained student-centered discussion is featured in the following episode.

Episode Ill is only a small part of the entire sequence surrounding the question of the orientation in which Jeff and John's bridge should be displayed at the local science museum. Several peers had concerns with the procedure Jeff and John had chosen, which was to test their bridge by turning it upside down. Throughout the 13-minute presentation and discussion of the project, students brought this topic up repeatedly. Here, both Ron and Stan were concerned with the discrepancy between making the claim of the bridge's strength (347 blocks, line 111.13) when it was tested upside down (lines III.! and III.I3), and when it was displayed right side up. The teachers' contributions were requests for further elaborations (lines 111.16 and III.21) or comments (line Ill.3), or-particularly in Tammy's case, in which she did not want presenters to be embarrassed, or conflicts of any sort-to intervene in some way to guarantee the flow of the conversation (line Ill.7). The important questions, however, were posed by the students themselves (lines 111.1, 111.4, and III.13). In terms of content, questions and answers addressed issues relating to testing procedures (lines Ill. I and 11.13), the design's purposes, and user 
Episode II

\begin{tabular}{lcc}
\hline Utterance & $\begin{array}{c}\text { Type of utterance } \\
\text { (Appendix A) }\end{array}$ & $\begin{array}{c}\text { Knowledge domain } \\
\text { (Table I) }\end{array}$ \\
\hline
\end{tabular}

I. Gitte: What was the biggest problem you had so far?(...)

2. Shelly: Getting the glue gun

3. Gitte: So that's been a real restricting factor for you $=$

\begin{tabular}{|c|c|}
\hline $\mathrm{R}_{1}$ (init) & 5.3 \\
\hline A. & 5.1 \\
\hline $\begin{array}{l}\text { Coni } 1.1 \text { [conf: } \\
\text { Al1] }\end{array}$ & \\
\hline $\mathrm{A}_{12}\left[\mathrm{elab}: \mathrm{A}_{11}\right.$ & $5.1,4.2(2.2)$ \\
\hline $\mathrm{R} 2\left[\right.$ just: $\mathrm{A}_{12}$ ] & $\begin{array}{l}\text { 3.2(1.2), technique } \\
\text { used, implying } \\
\text { property of mate- } \\
\text { rial }\end{array}$ \\
\hline A 2.1 & 4.2. 5.3 \\
\hline
\end{tabular}

6. Shelly: We thought, I think we were supposed to only use a glue gun, and since when you asked me to tape it, you did it all up there, and it could still wobble around, so I decided.

7. Gitte: Oh, I see, but what is it about the glue that's really good?

8. Shelly: Well, this is (.)

9. Clare: The glue is strong.

10. Shelly: Yes, it is really strong, and it helped us a lot. That's why we decided to use a glue gun. We only used one drop of glue last time we used it, and it was strong enough.

II. Gitte: That's right, you used different, you used pins and tape the last time.

12. Shelly: Pins, tape and clay. Clay doesn't stick as well as pins.

13. Clare: We used the clay so the, hm::, so the, the.

14. Shelly: In the place of the $=$

15. Clare: =Yeah, it was tending to dry out.

16. Shelly: And then I got that idea from the engineering technique board.

17. Gitte: Oh, is that right?

18. Shelly: 'Cause one, you know all the paperclips have something on the back, the one with the paperclip and the spaghe//tti]

19. Gitte: Yes]=

20. Shelly: =How's it's got the clay in the inl/sides?]

21. Gitte: Yes, yes], oh that's interesting. Hm:::

22. Are you happy with your materials?
4.2. 5.3

R [elab: ${ }_{2} \mathrm{~d}$

AJ.I

AJ. 2

A 3.3

1.2 , property of material

1.2

$1.2,3.2,(4.2)$

Cont3.dconf,

elab: $A_{33}$ ]

A3.4[elab: $A_{3.3}$ ]

$3.2,1.2$

A3.

A3.6

A 7

A3R

Cont.

A.<

3.1. 3.2

Cont

A .IO

3.2

Conf

$\mathrm{R}_{4}$ (init)
4.2( 1.2) Operating performance, implicitly about property

specifications. As in this episode, Gitte's questions were thus requests for elaborations or justifications of topics raised in students' accounts.

Drawing Out Canonical Content Knowledge. There are moments in the transcript which can be used to construct less positive elements in Gitte's questioning. Often, these moments occurred when Gitte asked students to name and describe specific engineering techniques 
Episode Ill

Utterance

Type of utterance

(Appendix A)
Knowledge domain

(Table I)

I. Ron: Did you write anything in the description

$\mathrm{R} 1$ (init)

3.1

thing about (.) about that it held that many, but upside down?

2. Jeff: No, we didn't write upside down.

3. Tammy: It would be an interesting thing to add. (.) Dan.

4. Dan: Is there people or cars on your bridge?

5. Jeff: We don't know, it doesn't really matter if it is for people or cars.

6. John: Before $=$

7. Tammy: =It's the idea of a bridge, right?

8. Jeff: Yes.

9. John: Before we put the braces on, we were gonna make people through there and cars go up on top but it wouldn't be strong enough, se we put the braces $=$

10. Jeff: ='Cause, 'cause like that it would be like an elevator to bring $I /$ people up]

II. Tammy: Oh, cool]

12. Jeff: But now we say, well at least it's a bridge and we don't care what bridge it is. $(\ldots ; \ldots ; \ldots)$. Stan?

13. Stan: When you will display it, are you going to put it upside down or the way you got the 347 blocks or you're gonna put it?

14. Jeff: In the case, we actuallya re going to put it like this, I think, that would make it look better. (.)'Cause if we have it like this, and you're just passing by, you probably think it is like a flight control or something.

15. (laughter, students and teachers)

16. Tammy: Flight control? (laughs)

17. Jeff: Yeah, like this.

A11

Com, Des

$\mathrm{R}_{2}$ (init)

A2.1

A2.2

R3(conf)

A31

A2.2

$2.2,2.1^{\prime} 4.2(2.2)$

$\mathrm{A}_{23}$ (elab)

Cont2

$\mathrm{A}_{23}$ (elab), Des

$\mathrm{R}_{4}$ (elab)

A41

$\mathrm{R}$ (conf)

As. I

As. 2

Des

Des

$\mathrm{R}_{6}(\operatorname{expl})$

A6. 1

2.3

A6.2

2.3

A6.3

(related to the strengthening of materials or design elements) by using canonical engineering discourse. In these situations, students usually guessed, or simply admitted their lack of knowledge concerning the item ("Do you know the name of this technique?" "No.").

Gitte's questioning for specific canonical descriptions was entirely consistent with her belief that children spontaneously invented many engineering techniques, or knew about them, but that it was her duty to draw this knowledge out. By drawing this knowledge out over and 
over again-that is, by getting children to talk engineering-Gitte believed the children would eventually include develop a canonical engineering discourse. This drawing out is evident in Episode IV. In this episode, Gitte tried to elicit specific answers (consistent with her belief that once this knowledge is made public in the classroom forum, it could be appropriated by all students) and evaluated children's responses in those terms. The initial remark left no doubt that the answers to her question could be found in a previous conversation ("that we've talked about before" [line IV.I]). Subsequent student responses were evaluated in terms of these still-hidden solutions. This evaluation was implicit in the indication of incompleteness in comments such as "Yes, that's one. What's another one ... ?" (line IV.3), or "Good. Is there another technique that you are not getting yet?" (line IV.7). On the other hand, Gitte felt justified because, as she argued, it was through such recitation that the students actually learned so much of engineering design-related content knowledge in this class. Gitte was supported in this by Tammy, who observed that the students in this study had learned much more than those to whom she had taught parts of the unit before.

Although these interactions show some similarity with IRE sequences, there is a difference. Children's answers were not evaluated against the external standard of canonical knowledge. The interactions here were more like "I see something that you don't see"; Gitte's question concerned the artifact present before the children, and most frequently, items which had already been labeled and discussed by the children. Evidence for this interpretation in the present situation exists in the fact that all three features mentioned by the children-Damian's triangles (line IV.2), Simon's technique of fastening beams (line IV.6), and Jeff's platform-had been introduced by the students to the shared classroom discourse, precipitated by their experience during the construction of artifacts.

Although Gitte took the opportunity to introduce items from canonical engineering discourse, this did not mean that children automatically appropriated it into their own discourse. Rather, she found (as did her partner Tammy) that it took an enormous effort in those cases where they really wanted children to appropriate an aspect of engineering discourse such as

Episode IV

\begin{tabular}{ccc}
\hline Utterance & $\begin{array}{c}\text { Type of utterance } \\
\text { (Appendix A) }\end{array}$ & $\begin{array}{c}\text { Knowledge domain } \\
\text { (Table I) }\end{array}$
\end{tabular}
I. Gitte: So they have used a couple of techniques here that we've talked about before. Do you know what they are? $[\ldots ; \ldots)$ Damian?

$\mathrm{Rl}$ (init) $\quad 5.2$

2. Damian: Triangles.

3. Gitte: Yes, that's one, what's another one? $[\ldots ; \ldots ; \ldots]$ A really important technique ((points at Simon))

4. Simon: Ah::. the stability(.) because when it wasn't, when it was (.) strong=

5. Gitte: =And how did they make it stable?

6. Simon: Well you put this around it, so it can hold(.) hold a ball and it stay up.

7. Gitte: Good, good, there is another technique that youa re not getting yet?=

8. Jeff: $=$ A platform on the top $=$ ((shouts out answer without being designated))

9. Gitte: $=$ Yes.

$\begin{array}{ll}A & 5.2 \\ \mathrm{R}_{2} \text { (elab), Des } & 5.2\end{array}$

A2.1

2.2

RJ(expl) $\quad 3.1$

AJ.I 3.1

R4(elab) $\quad 5.2$

A4.1 5.2

E 
making triangular braces (triangles) or the testing of structures to find their weak spots by bringing the models to catastrophic failure. Similarly, neither laminating nor cantilevering were readily appropriated by the children. However, their own invention of layering was a dominant feature of their engineering-related discourse (as evidenced in their conversations about their artifacts during construction and as part of 15 students' glossaries).

In summary, the analysis of Gitte's questions in terms of their engineering knowledge revealed a complex and varied typology that included five major items: knowledge related to the natural world, design practice, development and testing of the design, final product, and knowledge itself. During her interactions, Gitte made sure that the students talked about issues related to the five domains by asking appropriate questions. Thus, as students' accounts of their project and the design process became more complete, Gitte decreased the frequency of her questions and covered fewer domains. Gitte's questions were not of the devised format type and her questioning could not be modeled by the IRE sequence.

\section{Responses and Reactions to Questions}

The episodes cited so far indicated two trends not reported by research on questioning in traditional classrooms. First, although Gitte did not evaluate children's answers (as in the IRE sequence), her authority as a teacher was undisputed. Thus, in this classroom teacher authority was asserted and maintained by means other than the IRE sequence often linked to teacher control (Lemke, 1990; Lynch et al., 1983; Poole, 1994a). Here, the fact that Gitte questioned and students answered is symptomatic of authority rather than a means of control. Second, although initiations requested children's own topics of interest, the subsequent questioning sequence clearly pursued the elicitation of discursive accounts that included the topics of properties of materials, techniques to change them, and design principles and configurations. Thus, although question sequences began with students' topical interests, Gitte ultimately controlled the topic (especially in the initial design phases of a project) by means of contingent queries that led to the canonical knowledge domains previously identified by Gitte.

Interacting with these contingent queries, and another form of discourse control, was Gitte's tendency to interrupt students' accounts by wrestling away the speaking tum. This wrestling away occurred in two ways: either Gitte latched on so that a student could not complete his or her tum (lines 1.5, Il.5, IV.5, and IV.9), or she overlapped with the student, which had the same effect (line I1.21). It was quite clear that Gitte wrestled away students' turns because of her concerns for asking students to elaborate or justify their statements (her contingent queries). In this, Gitte may be seen as asserting her right to interrupt others' discursive contributions. This points to an asymmetric relationship between participants which is constructed-in the double complicity of the teacher's assertion and the students' submissionrather than existing ontologically prior to the interaction (Roth, 1993).

However, the situation changed during whole-class discussions. In many instances, especially later in the unit, Gitte's participation in the discussion was similar to that of the other students. In Episode Ill, Gitte's question (line III.21) was but one of the many Jeff and John were asked to answer. Rather than wrestling the speaking tum away from a student, Gitte had waited until Jeff designated her as the next speaker. By that time, she felt that students began to ask each other those questions which initially only she had asked. During Jeff and John's presentation, crucial issues surrounding the testing procedures they had used were questioned by their peers. Ron's (line III.!) and Stan's questions (line III.13) about the description and presentation of Jeff and John's project at a planned exhibit directly related to the discussion of 
their controversial testing procedure (the bridge was tested upside down). At this point in the curriculum, the students had already appropriated specific question stems previously modeled by Gitte. Thus, students began to ask questions such as, "What was your biggest problem and how did you solve it?" and "What did you do when you were struggling?" (both questions relate to learning process, TI-5.3), or questions more specifically to configurations: "If you cut the connecting string, would the whole thing fall over?" (T1-3.3, predicting test outcomes). In these cases, the children's questions themselves were no longer requesting factual information, but probed aspects of knowledge from different categories of the typology.

The whole-class discussions featured in Episodes III and IV illustrate another important aspect about this classroom: Girls contributed little on their own or were almost never selected as next speakers either by teachers (such as Gitte, as shown in Figure 1) or by other children (Roth, 1995). In Episode IV, Gitte designated a boy as next speaker twice (line IV.1 and IV.3), and Jeff answered one of her question simply by latching on $("=")$ without previously being designated as the next speaker. In Episode III, either a boy (Ron, Dan, and Stan) or a teacher took, or was designated to take, the next tum (lines III.3, Ill.12, III.20, and 111.21). We observed only one instance during the 13-week period-a small-group session with 3 boys and 3 girls-when Gitte actually achieved a gender balance in designating respondents. Here, both boys and girls complained. The girls indicated that they did not want to be selected as frequently; the boys complained that Gitte gave preference to the girls. Thus, whereas our videotapes provide ample evidence that girls were full and uninhibited discourse participants when they talked to each other or with one of the teachers, the participative pattern in whole-class situations was entirely different.

\section{Discussion}

The EfCS curriculum was developed so that elementary school children could find out about and have positive first experiences with engineering. Many activities in the program were designed as open-ended engineering problems in the context of which children could learn to work and solve problems in a collaborative manner. This provided students with opportunities for practicing tool-related and engineering practices and developing engineering design discourses. In the context of the children's artifact-related experiences, the teacher-student conversations had the quality of exploratory talk, the teacher did not pursue evaluation of student contributions, and tum-taking rules other than IRE sequences could be observed. Thus, in this student-centered learning environment, teacher questioning had functions different from traditional classroom practices, such that the IRE sequence was a poor model for the teacher's questioning. In this, the present findings support those from a study with much younger children (Orsolini \& Pontecorvo, 1992).

The data illustrated in Episodes I through IV provide supportive evidence for the claim that in many respects Gitte asked genuine questions: she (a) did not know the requested information, (b) believed that students could provide the information requested, (c) was genuinely interested in the requested information, and (d) believed the students would provide the answer. In this, Gitte conformed to fundamental assumptions of questioning which are nevertheless violated by most teachers (Graesser \& Person, 1994; Lynch et al., 1983). Of course, the motivation for questions in most everyday situations is to further one's own causes, whereas the motivation for Gitte's questions (like that in counseling sessions) was to benefit someone else: here, to facilitate children's learning. The few moments during which Gitte tried to elicit specific items related to canonical engineering discourse (typology items TI-5.2a) encouraged student guessing; several 
observers characterized these moments as rather awkward and not compatible with the other aspects of the course. While Gitte's interactions with students were usually characterized by the absence of any evaluation, she unmistakably evaluated students' contributions when she sought to elicit specific items.

In the present setting, the most visible aspect of children's learning, aside from their development of tool-related practices, was their competence in talking about topics related to design in the domain of structural engineering (Roth, 1996a, 1996b). In my interpretation of the data, the development of children's discourse was made possible primarily by Gitte's questioning; this assessment parallels that made by other observers in this classroom. The contingent queries which were rather frequent during initial stages of the projects began to fade as children's (hi)stories of their designs addressed an increasing number of engineering-related issues (as they appear in Table 1). These contingent queries had a function not unlike those used in effective tutoring. In tutoring, questions are employed to coach students through a solution path (McArthur, Stasz, \& Zmuidzinas, 1990). The tutor queries students to assess their knowledge, confidence, understanding, and current status of the problem, or to focus students' attention on specific aspects of the problem text, their own writing, and so on. These questions scaffold students' efforts in selecting and taking certain paths leading them to the solution. In the present instance, Gitte's questioning can also be understood as scaffolding. Here, however, its purpose was to allow children to construct stories or accounts of and about engineering. During the initial stages of students' designs, questioning was more frequent, purposefully addressing many issues relating to tool-related and discursive practices of engineering (pertaining to both canonical practices and those idiosyncratic to this classroom community). In this way, students developed a discursive competence that overwhelmed the visiting elementary teachers ("The kids were able to talk about the beams and supports and stays; and I thought I was having a difficult time, when I wanted to speak to them about their bridges, because I didn't have the vocabulary that they did").

Gitte decreased her support as students' accounts of their work and plans became longer and more complete. This lessening was apparent from all transcripts and is also observable in the episodes used here. Interacting with this lessening support was a change in the questions' content. Because students already talked about many issues without being prompted by Gitte's questions, these questions were also from fewer domains of the typology. This was especially evident from the whole-class discussions to which Gitte often contributed only a question or two; the remainder of critical issues were either covered by the presenters or addressed as a question by other students (such as the issues surrounding Jeff and John's controversial testing procedure, which was repeatedly raised, among others in Episode III).

The view of teacher questions as scaffolds underscores the social nature of individual and shared engineering-related discourses; that is, questions constituted teachers' contributions to the social construction of the discourse. While the projects and the conversations over and about the artifacts arose from children's interests, the competence to provide longer and more detailed engineering-based accounts cannot be understood separately from Gitte's questioning. However, this does not mean that Gitte was the key contributor of items for the shared language. Rather, many of the terms originated with the students and from the domain of everyday discourse. Gitte's work consisted in providing opportunities so that items originating with individual students became shared at the classroom level (such as $X$-shape created by Stan and Tim, stay introduced by Jeff, or triangle proposed by Ron). During whole-class settings such as those featured in Episodes Ill and IV, and with Gitte's insistent questioning, many of these items were appropriated by an increasing number of students.

These features-increasing student competence, the scaffolding nature of the teacher's 
discourse contributions, and students' appropriation of questioning practices-are compatible with a Vygotskian sociocultural framework of learning (Roth, 1993). At the same time, this framework almost implies the teachers' control of the discourse, because it permits students to acquire the canonical practices of an existing discourse community. Other researchers question the teachers' control as a means of introducing students to canonical discourse (Lemke, 1990). However, the present setting gave children the opportunity to develop discursive practices beginning with their own experiences and based on their own language games.

The content analysis of Gitte's questions underscored the extended nature of her engineering design-related discursive practice. This discourse was not simply fact-based, in which case she would have asked questions about the properties of materials (TI-1.2) and names of engineering techniques (TI-2.2 and TI-5.2). Rather, it combined topics from five different domains of knowledge in engineering design related to materials, design practice, development and testing practice, performance of final products, and knowing and learning through design. In this, the subject matter covered by Gitte included dimensions nearly identical to those that had been identified for innovative engineering designers (Faulkner, 1994), although the extent of the engineering discourse was admittedly much more limited. Gitte's experience as curriculum designer, teacher, and observer of many construction sites and her interactions with engineers had enabled her to scaffold children's engineering design-related conversations so that they achieved great competence. On the basis of the data collected (and illustrated in Episodes I through IV), the claim that good question techniques require a great deal of competence in the discursive practices of the subject-matter domain appears to be justified. In this, the present study supports the claims made in high school biology classrooms (Carlsen, 1993). However, subject-matter competence in and of itself was insufficient.

The gender inequities in whole-class sessions were at the same time consistent with and elucidative of prior research (Scantlebury \& Kahle, 1993). Although both team teachers made sure that the learning environment was safe by suppressing any attempt of boys to put down girls (and there were only very few), Gitte never managed to bring about a significant increase in girls' participation during whole-class discussions. Whereas Gitte's practice of asking girls more factual questions was consistent with Scantlebury and Kahle's research, the present study showed that her practice was driven by a genuine concern for girls' cognitive needs. These concerns were motivated by Gitte's own experience and by her professional training related to learning styles. While Gitte's questioning during whole-class sessions did not appear to be favorable to gender equity (despite her declared concern), her instructional move to small-group interactions is typical for equitable teaching strategies (Scantlebury \& Kahle, 1993).

This study underscored the complexity of questioning as teaching practice, as a result of the interactions of content, context, and response/reaction dimensions, a complexity which resists reductionist approaches to understanding. For example, the interactions of context and content became quite clear when Gitte adjusted the content of her questioning to the perceived interest and emotional state of the students ("giddiness" of Andy, Simon, and Tim; Damian's "interest" in improving his bridge); content and response/reactions interacted as shown in the contingencies of her queries; and context and response/reaction interacted such as to assert Gitte's authority and control. This complexity also arises from the often competing demands set by a learning situation which is to be student-centered without compromising canonical content knowledge. Because of these interactions of a question's content with other dimensions of questioning, any improvement of subject-matter competence, for example, may be subverted in the presence of other beliefs. The aforementioned complexity raises important questions related to teacher preparation and professional development, which will be addressed in the next section. 


\section{Implications}

In the past, teacher enhancement projects often focused on individual aspects of classroom teaching such as (a) extending wait time (Tobin, 1986), a response/reaction dimension; (b) changing the context of questioning by making the tum-taking patterns culturally appropriate (Au \& Mason, 1983) or by providing support for implementing gender equity strategies (Scantlebury \& Kahle, 1993); or (c) providing science teachers with more content courses (Warren \& Roseberry, in press). Provided the results of the current study are transportable to other settings and teachers (transportability is interpretive research's equivalent of generalizability), they suggest that the issues are too complex to remedy poor questioning simply by changing one dimension of a teacher's knowledge. The complexity of the issues about changing questioningrelated practices became clear to us in the course of this study. Gitte was unable to change the frequency with which she designated girls as the next speaker, despite (a) her declared interest to provide girls with equal learning opportunities-and particularly to practice their engineering discourse during whole-class sessions; (b) the help Tammy provided by monitoring her questioning during class and through her own video analysis; and (c) the assistance Gitte received during debriefing and feedback sessions with myself. Furthermore, Gitte was at an advantage compared to most elementary teachers: She already had great competence and experience in content-related matters (as teacher, curriculum developer, and workshop provider, and through site visits).

Our collaborating teachers provided additional support for this contention. Tammy recurrently talked about the extent of her learning about proper questioning due to the participation in a collaborative practice with Gitte. Tammy explained,

After watching Gitte, I just improved dramatically. 1 realized that 1 was going nowhere fast, and I wasn't helping these kids at all with the kinds of questions. I could have done this unit without Gitte, but I would never be where I'm right now, with those kids; and the kids would have never made the bridges they made today.

Tammy pointed out repeatedly that the improvements in her questioning technique could not have come from reading sample questions in a teachers' manual, or by taking several university courses. While there are some conjectures that participation in practice will lead to meaningful and lasting learning (Bourdieu, 1990; Lave, 1993), an understanding of the mechanisms of such learning is only in its initial stage (Roth, 1995). Accordingly, newcomers and neophytes appropriate complex practices such as questioning by participating in the practice itself through some form of apprentice-mentor relationship with an experienced and competent practitioner. This would suggest that student teachers should learn questioning-as other aspects of teaching-by participating in the practice of teaching. Here, they could appropriate these complex practices in a setting where the responsibilities for teaching are distributed. Novice teachers could appropriate the specific cultural practices of teaching that come from participating in practice, rather than through inculcation of new sets of teaching strategies as is so often done in the name of teacher development (Warren \& Roseberry, 1995).

An important role in the development of teachers' practices may be played by arranging for groups in which these practices are the focus of discussions. At Simon Fraser University, groups including student teachers, resident teachers, and university-based supervisors (seconded teachers or professors) engage in discussions of the novices' teaching practices. Through these discussions all participants, but especially novice teachers, may develop new discourses to understand their own practices. Researchers could play a particular role in the promotion of reflection on existing practices and possible alternatives when participants decide that change is 
appropriate. As one reviewer pointed out, researchers could then facilitate the construction of theory, metalanguages, and general propositions that could be tested by both experienced and novice teachers. Such a move would situate teaching practice in an action-research perspective, and keep the continuous evolution of practices in constant focus.

From a methodologic perspective, the present findings should have consequences for how teacher questioning is investigated (under the provision that my findings are transportable to other contexts, teachers, and studies). This study has shown that the frequency and content of questions changed as the students progressed through each project and developed increasing discursive competence. Establishing frequency counts of questions or content would have been insensitive to the context-related changes necessitated by the changing context in which Gitte questioned. In fact, counting frequencies to provide evidence for the gender-related imbalance in the designation of next speakers was insensitive to Gitte's other pedagogic concern-providing a safe learning environment for girls in intellectual and social terms. Thus, models of teacher questioning need to account for the constantly changing contexts at various levels (microcontext of individual conversations and macrocontexts accounting for issues at the classroom level, or the curriculum to be enacted).

From my perspective, the most interesting and pressing questions raised by this study are related to neophyte teachers' appropriation of complex practices such as productive questioning in specific subject-matter domains. Given a mentor-apprentice relationship, I am interested in questions such as, What are the mechanism by means of which complex questioning practices are appropriated? How do the interactions between context, content, and response/reactions shift with increasing competence in questioning? and, How do knowledge and beliefs of mentor and apprentice teacher interact during their collaboration in practice?

This work was made possible by Grants 812-93-0006 and 410-93-1127 from the Social Sciences Humanities Research Council of Canada. The author's sincere thanks go to Sylvie Boutonne for significant help during data collection, transcription of the videotapes, and preparation of the manuscript. The author is grateful to the teachers and students for their participation in this project, and to Jay Lemke, who provided valuable feedback on an earlier version.

Appendix A

\section{Transcription Conventions}

YES oObject velocities are higho $[\ldots ; \ldots)$

(.)

that:

(alien?)

(?'??)

Grea:::t

G: throw it//up]

E: What]

?!.
Words in caps, louder than usual talk

Degree signs to indicate low volume, almost inaudible talk

Each triplet of periods in square brackets corresponds to I second of silence

Audible pause, but shorter than 0.5 seconds

Equal sign indicates "latching," i.e., the normal period of silence between the end of one speaking tum and the beginning of the next does not exist

Italics to indicate emphasis in speech

Possible but not certain hearing of a word

Words which could not be heard

Lengthening of phoneme

Overlap of two speakers; the overlap begins at "//" and ends at ")"

Punctuation to indicate questions, exclamations, stops, and full stops in speech 


\section{Appendix B}

Typology of Utterances

\begin{tabular}{|c|c|}
\hline Code & Explanation \\
\hline $\mathrm{R}, \mathrm{A} 2$, & First request, question in the transcribed episode \\
\hline Cont $_{12}$ & Third answer to the second question in the transcribed episode \\
\hline $\mathrm{R}_{1} \quad$ (just) & Second continuer following first question \\
\hline $\mathrm{R}_{2}(\mathrm{elab})$ & Request for justification \\
\hline $\mathrm{R}_{3}(\operatorname{expl})$ & Request for elaboration \\
\hline $\mathrm{R}_{1}$ (init) & Request for explanation \\
\hline Com & Initiation of a new topic \\
\hline Des & Comment \\
\hline & Designation of next speaker \\
\hline
\end{tabular}

\section{References}

Au, K.H., \& Mason, J.M. (1983). Cultural congruence in classroom participation structures: Achieving a balance of rights. Discourse Processes, 6, 145-167.

Berger, P., \& Luckman, T. (1967). The social construction of reality. London: Allan Lane.

Bourdieu, P. (1990). The logic of practice. Cambridge, UK: Polity Press.

Carlsen, W.S. (1988). The effects of science teacher subject-matter knowledge on teacher questioning and classroom discourse. Unpublished doctoral dissertation, Stanford University, Stanford, CA.

Carlsen, W.S. (1991). Questioning in classrooms: A sociolinguistic perspective. Review of Educational Research, 61, 157-178.

Carlsen, W.S. (1993). Teacher knowledge and discourse control: Quantitative evidence from novice teachers' classrooms. Journal of Research in Science Teaching, 30, 471-481.

Erickson, F. (1982). Money tree, lasagna bush, salt and pepper:. Social construction of topical cohesion in a conversation among Italian Americans. In D. Tannen (Ed.), Analyzing discourse: Text and talk (pp. 43-70). Washington, DC: Georgetown University Press.

Faulkner, W. (1994). Conceptualizing knowledge used in innovation: A second look at the sciencetechnology distinction and industrial innovation. Science, Technology, and Human Values, 19, 425-458.

Garfinkel, H. (1991). Respecification: evidence for locally produced naturally accountable phenomena of order*, logic, reason, meaning, method, etc. in an as of the essential haecceity of immortal ordinary society, (1)-an announcement of studies. In G. Button (Ed.), Ethnomethodology and the human sciences (pp. 10-19). Cambridge: Cambridge University Press.

Geertz, C. (1975). On the nature of anthropological understanding. The American Scientist, 63, 47-53.

Graesser, A.C., \& Person, N.K. (1994). Question asking during tutoring. American Educational Research Journal, 31, 104-137.

Guba, E., \& Lincoln, Y. (1989). Fourth generation evaluation. Beverly Hills, CA: Sage.

Hare, I. (1991). Children designers: Interdisciplinary constructions for learning and knowing mathematics in a computer-rich school. Norwood, NJ: Ablex.

Harlen, W. (1985). Primary science: Taking the plunge. London, UK: Heineman.

Heidegger, M. (1977). Sein und zeit [Being and time]. Ttibingen, Germany: Max Niemeyer. 
Kafai, Y.B. (1994). Minds in play: Computer game design as a context for children's learning. Hillsdale, NJ: Lawrence Erlbaum Associates.

King, A. (1994). Guiding knowledge construction in the classroom: Effects of teaching children how to question and how to explain. American Educational Research Journal, 31, 338-368.

Lave, J. (1993). The practice of learning. In S. Chaiklin \& J. Lave (Eds.), Understanding practice: Perspectives on activity and context (pp. 3-32). Cambridge: Cambridge University Press.

Lemke, J.L. (1990). Talking science: Language, learning and values. Norwood, NJ: Ablex

Publishing.

Lynch, M., Livingston, E., \& Garfinkel, H. (1983). Temporal order in laboratory work. In K.D. Knorr-Cetina \& M. Mulkay (Eds.), Science observed: Perspectives on the social study of science (pp. 205-238). London: Sage Publications.

McArthur, D., Stasz, C., \& Zmuidzinas, M. (1990). Tutoring techniques in algebra. Cognition and Instruction, 7, 197-244.

Morrison, K. (1981). Some properties of "Telling order designs" in didactic inquiry. Philosophy of the Social Sciences, 11, 245-262.

Ochs, E. (1979). Introduction: What child language can contribute to pragmatics. In E. Ochs and B.B. Schieffelen (Eds.), Developmental pragmatics (pp. 1-17). New York: Academic Press.

Orsolini, M., \& Pontecorvo, C. (1992). Children's talk in classroom discussions. Cognition and Instruction, 9, 113-136.

Poole, D. (1994a). Routine testing practices and the linguistic construction of knowledge. Cognition and Instruction, 12, 125-150.

Poole, D. (1994b). Differentiation as an interactional consequence of routine classroom testing. International Journal of Qualitative Studies in Education, 7, 1-17.

Redfield, D.L., \& Rousseau, E.W. (1981). A meta-analysis of experimental research on teacher questioning behavior. Review of Educational Research, 51, 237-245.

Rorty, R. (1989). Contingency, irony, and solidarity. Cambridge: Cambridge University Press.

Roseberry, A.S., Warren, B., \& Conant, F.R. (1992). Appropriating science discourse: Findings from language minority classrooms. The Journal of the Learning Sciences, 2, 61-94.

Roth, W.-M. (1993). Metaphors and conversational analysis as tools in reflection on teaching practice: Two perspectives on teacher-student interactions in open-inquiry science. Science Education, 77, 351-373.

Roth, W.-M. (1994). Experimenting in a constructivist high school physics laboratory. Journal of Research in Science Teaching, 31, 197-223.

Roth, W.-M. (1995, April). A case study of the theoretical and practical knowledge constructed by two teachers while team-teaching an engineering unit. Paper presented at the annual meeting of the National Association for Research in Science Teaching, San Francisco, CA.

Roth, W.-M. (1996a). Art and artifact of children's designing: A situated cognition perspective. The Journal of the Learning Sciences, 5, 129-166.

Roth, W.-M. (1996b). Knowledge diffusion in a grade 4/5 classroom during a unit on civil engineering: An analysis of a classroom community in terms of its changing resources and practices. Cognition and Instruction, 14, 179-220.

Roth, W.-M., \& Bowen, G.M. (1995). Knowing and interacting: A study of culture, practices, and resources in a grade 8 open-inquiry science classroom guided by a cognitive apprenticeship metaphor. Cognition and Instruction, 13, 73-128. 
Samson, G.E., Strykowski, B., Weinstein, T., \& Walberg, H.J. (1987). The effects of teacher questioning levels on student achievement: A quantitative synthesis. Journal of Educational Research, 80, 290-295.

Scardamalia, M., \& Bereiter, C. (1992). Text-based and knowledge-based questioning by children. Cognition and Instruction, 9, 177-199.

Scantlebury, K., \& Kahle, J.B. (1993). The implementation of equitable teaching strategies by high school biology student teachers. Journal of Research in Science Teaching, 30, 537-545.

Schon, D.A. (1987). Educating the reflective practitioner. San Francisco: Jossey-Bass. Smith, E.L., Blakeslee, T.D., \& Anderson, C.W. (1993). Teaching strategies associated with conceptual change learning in science. Journal of Research in Science Teaching, 20, 111-126.

Suchman, L.A., \& Trigg, R.H. (1991). Understanding practice: Video as a medium for reflection and design. 1n J. Greenbaum \& M. Kyng (Eds.), Design at work: Cooperative design of computer systems (pp. 65-89). Hillsdale, NJ: LEA.

Tobin, K.G. (1986). Effects of teacher wait time on discourse characteristics in mathematics and language arts classes. American Educational Research Journal, 23, 191-200.

van der Meij, H. (1987). Assumptions of information-asking questions. Questioning Exchange, I, III-117.

Warren, B., \& Roseberry, A.S. (1995). Equity in the future tenses: Redefining relationships among teachers, students, and science in linguistic minority classrooms. In W. Secada, E. Fennema, \& L. Byrd (Eds.), New directions in equity for mathematics education (pp. 298-328). New York: Cambridge University Press.

Winne, P.H. (1979). Experiments relating teachers' use of higher cognitive questions to student achievement. Review of Educational Research, 49, 13-50. 